\title{
Evolução temporal e espacial da desembocadura lagunar de Cananéia (SP)
}

\author{
Moysés G. TESSLER; Kenitiro SUGUIO ${ }^{1}$; Michel M. de MAHIQUES \& ValdenirV.FURTADO
}

Instituto Oceanográfico da Universidade de São Paulo

(Caixa Postal 9075, 01051 São Paulo, SP)

- Abstract: Shoreline changes of the Cananéia-Iguape lagoonal system (São Paulo State) have been reconstructed in detail through interpretation of aerial photographs since the 1950's. The most important changes are the recession of the northern and the advancement of the eastern side of the sandy segment of Cardoso Island, headed to the ocean, and the erosion of the lagoonal margin in the southern section of Comprida Island. The geomorphologic evolution of the southcoast of São Paulo shows to be closely related to the coastal hydrodynamic mechanisms induced by the atmospheric circulation of this part of the South American continent. The interaction of these phenomena is fundamental not only to the mobility of sandy sediments, that obstruct or change the displacement of the channels that lead to the lagoonal area, but also for the erosive and depositional processes that affect the ocean side of Cardoso and Cananéia islands.

Descriptors: Coastal erosion, Cananéia outlet, Quaternary, Brazil.

Descritores: Erosão das costas, Barra de Cananéia: SP, Período Quaternário.

\section{Introdução}

A desembocadura lagunar de Cananéia localizada próxima à cidade do mesmo nome (Fig. 1), constitui a principal via de acesso a esta regiāo lagunar do litoral sul paulista e sua evolução vem sendo acompanhada desde o período da colonização portuguesa.

Alguns estudos, realizados a partir da década de 50, têm mostrado modificaçōes significativas na configuraçāo geral deste canal, bem como das áreas adjacentes e levaram alguns autores a vizualizarem tendências evolutivas através do tempo (Sadowsky, 1952, 1954; Petri \& Suguio, 1971; Suguio \& Tessler, 1983, e outros).

Sadowsky (1954), ao verificar uma desproporção entre a maior largura observada $(1200 \mathrm{~m})$ e a maior profundidade $(20 \mathrm{~m})$, da seção do canal principal desta desembocadura lagunar, sugere ser esta área de acesso

(1) Instituto de Geociências da USP.

Constr. $n^{2} 713$ do Inst. oceanogr. da Usp. relativamente diminuta em comparação à área total abrangida pelo sistema lagunar .

Os levantamentos batimétricos realizados pela Diretoria de Hidrografia e Navegação do Ministério da Marinha (DHN - MM) e pelo Laboratoire Nationale d'Hydraulique Chatou/Departamento de Águas e Energia Elétrica do Estado de São Paulo (DAEE - SP, 1956, apud Suguio \& Tessler, op. cit. ) demonstraram que, embora as profundidades máximas das regiōes marinhas e lagunares, adjacentes ao canal principal da desembocadura lagunar, não ultrapassem os 8 metros, este canal sempre conservou, ao longo do tempo, profundidades máximas próximas de 20 metros. Tal fato levou Suguio \& Tessler (op. cit.) a sugerirem uma origem relacionada a um paleovale submerso durante a transgressão holocênica. Em GEOBRÁS (1966), o mesmo fato é explicado por um processo de abatimento estrutural.

Qualquer que seja sua origem, a persistência dessas características, pelo menos ao longo dos últimos 50 anos, poderia indicar que, durante este período, não tenha havido transferência muito importante de sedimentos junto ao fundo, entre as regiōes marinha e lagunar. 


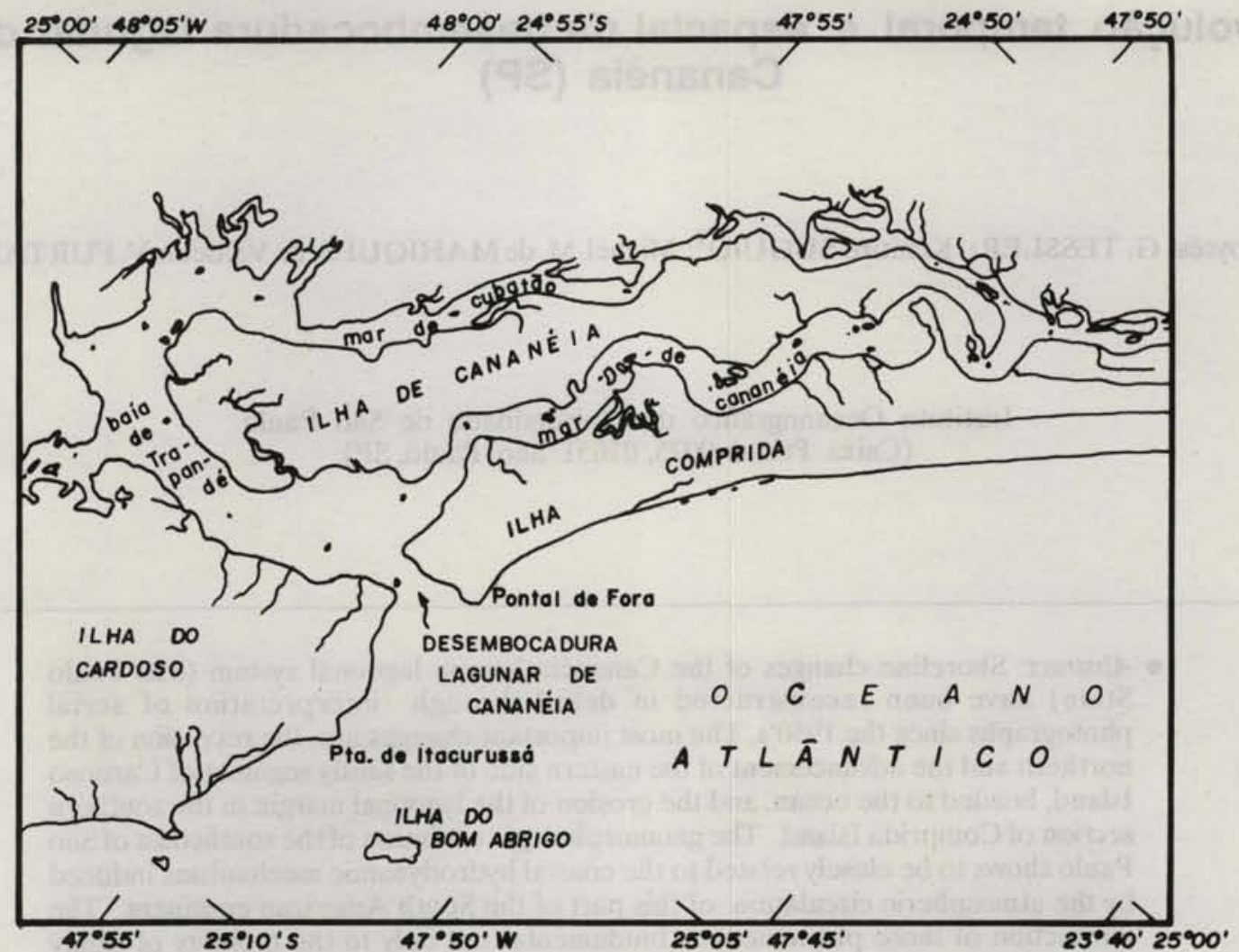

Fig. 1. Mapa de localização da desembocadura lagunar de Cananéia.

De acordo com Sadowsky (1954), a extremidade mais a leste da Ilha do Cardoso, Ponta do Perigo, tem estado submetida a processos erosivos por um longo período, acarretando com isso um deslocamento da linha de costa atrás dessa feiçāo arenosa. Segundo o autor, este recuo seria o responsável pelo embate das ondas em locais cada vêz mais à retaguarda da Ilha Comprida, ocasionando acentuada erosão dos depósitos arenosos ali localizados.

Associada ao processo erosivo das margens do canal, Sadowsky (op. cit.), refere-se ao crescimento de uma ilha arenosa próxima à praia da Ilha do Cardoso, indicando existir uma área fonte no fornecimento de sedimentos situada a SSW, cujos materiais se juntariam às areias erodidas das margens do canal principal. Esses mecanismos seriam os responsáveis pela formação dos bancos arenosos submersos que dificultam $o$ acesso de embarcaçōes à regiāo lagunar.

Petri \& Suguio (1971), retomando a questão da configuração das margens do canal e usando informaçōes obtidas de fotos aéreas e trabalhos de campo, admitem que, embora a tendência da costa seja de crescimento às expensas do mar, atenuando os recortes litorâneos, localmente correntes de maré e ventos dominantes podem rapidamente erodir as porçōes menos resistentes. Desta forma, os autores afirmam que a erosão da costa leste da Ilha do Cardoso, cuja magnitude foi tal que sua projeção de direção noroeste passa a oeste da Ponta da Trincheira penetrando no mar de
Cananéia, foi originada pela açāo de correntes longitudinais vindas de sudeste.

Posteriormente, Suguio \& Tessler (1983) comparam as fotos aéreas de.1973, com a configuração da desembocadura lagunar de Cananéia, identificada por Petri \& Suguio (op.cit.), e concluíram que as tendências detectadas naquele estudo ainda permanecem .

Suguio \& Tessler (op.cit.) observaram também o crescimento dos bancos arenosos submersos, dispostos aproximadamente paralelos à desembocadura lagunar de Cananéia. Essas feiçōes arenosas submersas originaram-se, provavelmente, da interaçāo entre os sistemas de ondas incidentes, geradores de correntes longitudinais à costa, e das correntes de maré vazante, responsáveis por um grande volume de água que circula através da desembocadura lagunar.

\section{A evolução geomorfológica da desembocadura lagunar}

A superposição dos mapas de contorno da linha de costa, obtidos a partir de fotos aéreas de 1954 e 1981 sobre os resultados prévio e do Centro Tecnológico de Hidráulica ( CTH /USP - 1973), usando fotos aéreas de 1952,1962 e 1969 , permite interpretar os mecanismos hidrodinâmicos que condicionaram a evolução geomorfológica da desembocadura lagunar de Cananéia (Fig. 2). 


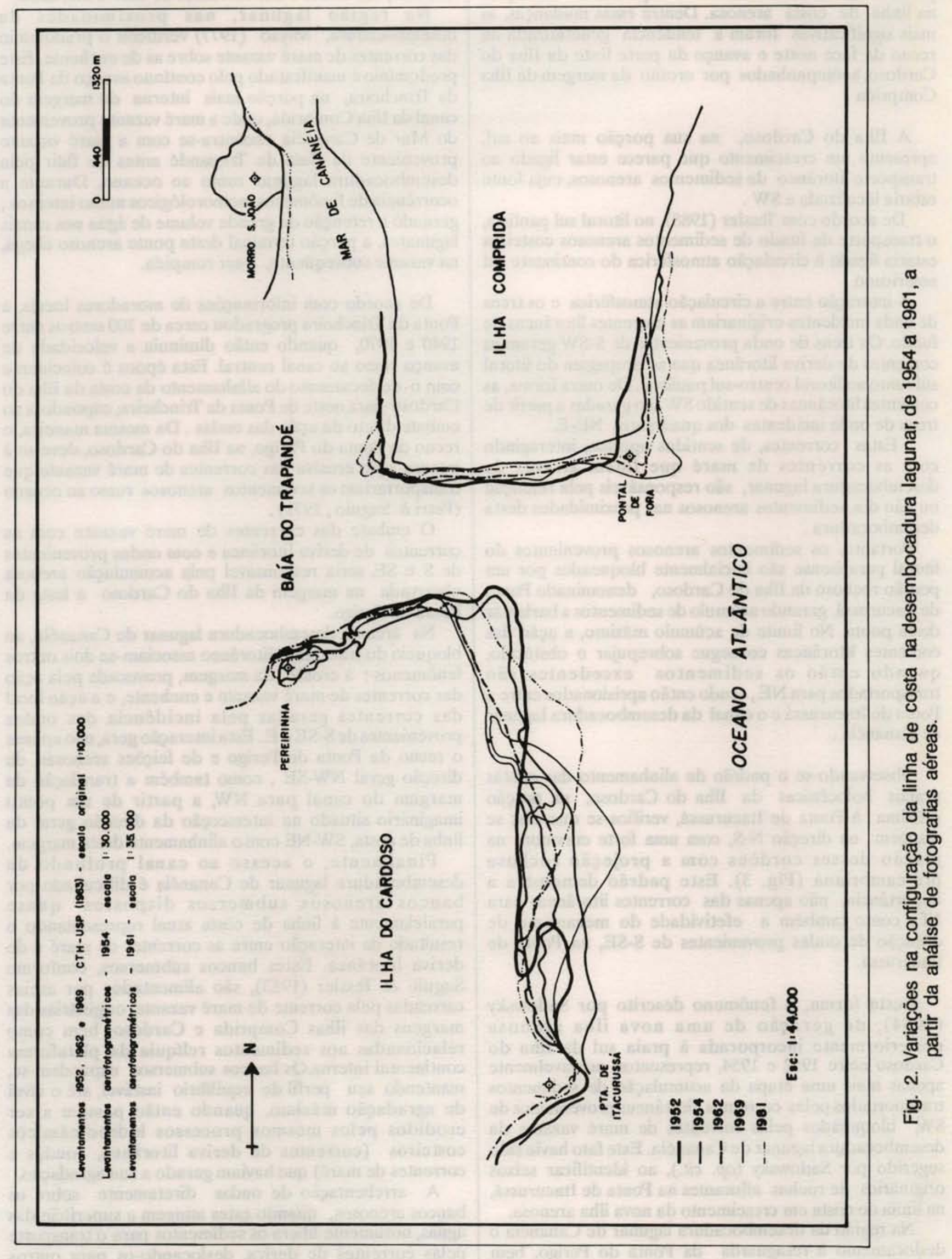


Esses estudos comparativos demonstraram que no período de 29 anos ocorreram importantes alterações na linha de costa arenosa. Dentre essas mudanças, as mais significativas foram a tendência generalizada de recuo da face norte e avanço da parte leste da Ilha do Cardoso, acompanhados por erosão da margem da Illha Comprida .

A Illha do Cardoso, na sua porção mais ao sul, apresenta um crescimento que parece estar ligado ao transporte litorâneo de sedimentos arenosos, cuja fonte estaria localizada a SW .

De acordo com Tessler (1988), no litoral sul paulista, o transporte de fundo de sedimentos arenosos costeiros estaria ligado à circulaçāo atmosférica do continente sul americano.

A interação entre a circulação atmosférica e os trens de onda incidentes originariam as correntes litorâneas de fundo. Os trens de onda provenientes de S-SW geram as correntes de deriva litorânea que se propagam do litoral sul rumo ao litoral centro-sul paulista. De outra forma, as correntes litorâneas de sentido SW são geradas a partir de trens de onda incidentes dos quadrantes NE-E.

Estas correntes, de sentidos opostos, interagindo com as correntes de maré que fluem através da desembocadura lagunar, são responsáveis pela retenção ou não dos sedimentos arenosos nas proximidades desta desembocadura .

Portanto, os sedimentos arenosos provenientes do litoral paranaense são inicialmente bloqueados por um pontâo rochoso da Illha do Cardoso, denominado Ponta de Itacurussá, gerando acúmulo de sedimentos a barlamar desta ponta. No limite de acúmulo máximo, a ação das correntes litorâneas consegue sobrepujar o obstáculo, quando então os sedimentos excedentes são transportados para NE, sendo então aprisionados entre a Ponta de Itacurussá e o canal da desembocadura lagunar de Cananéia .

Observando-se o padrão de alinhamento das cristas praiais holocênicas da Iltha do Cardoso, na porção próxima à Ponta de Itacurussá, verifica-se que elas se dispōem na direção $\mathrm{N}-\mathrm{S}$, com uma forte curvatura na junção desses cordōes com a projeção rochosa pré-cambriana (Fig. 3). Este padrão demonstra a importância, não apenas das correntes litorâneas para NE, como também a efetividade do mecanismo de difração de ondas provenientes de S-SE, na Ponta de Itacurussá.

Desta forma, o fenômeno descrito por Sadowsky (1954), de geração de uma nova ilha arenosa posteriormente incorporada à praia sul da Ilha do Cardoso entre 1952 e 1954, representou provavelmente apenas mais uma etapa da acumulação de sedimentos transportados pelas correntes litorâneas provenientes de SW, bloqueados pelas correntes de maré vazante da desembocadura lagunar de Cananéia. Este fato havia sido sugerido por Sadowsky (op. cit.), ao identificar seixos originários de rochas aflorantes na Ponta de Itacurussá, na linha de costa em crescimento da nova ilha arenosa.

$\mathrm{Na}$ região da desembocadura lagunar de Cananéia o deslocamento à retaguarda da Ponta do Perigo, bem como da face mais a oeste da Illha Comprida, constituem resposta à ação combinada das correntes de maré intensas, das ondas e das correntes de deriva litorânea.

$\mathrm{Na}$ região lagunar, nas proximidades da desembocadura, Miyao (1977) verificou o predomínio das correntes de maré vazante sobre as de enchente. Este predomínio é manifestado pelo contínuo avanço da Ponta da Trincheira, na porção mais interna da margem do canal da Ilha Comprida, onde a maré vazante proveniente do Mar de Cananéia encontra-se com a maré vazante proveniente da Baía de Trapandé antes de fluir pela desembocadura lagunar rumo ao oceano. Durante a ocorrência de fenômenos meteorológicos muito intensos, gerando a retenção de grande volume de água nos canais lagunares, a porção terminal deste ponto arenoso chega, na vazante subseqüente, a ser rompida.

De acordo com informações de moradores locais, a Ponta da Trincheira progradou cerca de 100 metros entre 1940 e 1970, quando então diminuiu a velocidade de avanço rumo ao canal central. Esta época é coincidente com o deslocamento do alinhamento da costa da Ilha do Cardoso para oeste da Ponta da Trincheira, expondo-a ao embate direto da ação das ondas. Da mesma maneira, o recuo da Ponta do Perigo, na Illa do Cardoso, deve-se à intensa ação erosiva das correntes de maré vazante que transportariam os sedimentos arenosos rumo ao oceano (Petri \& Suguio, 1971).

O embate das correntes de maré vazante com as correntes de deriva litorânea e com ondas provenientes de S e SE seria responsável pela acumulação arenosa observada na margem da Illha do Cardoso a leste da Ponta do Perigo.

$\mathrm{Na}$ área da desembocadura lagunar de Cananéia, ao bloqueio do transporte litorâneo associam-se dois outros fenômenos : a erosão da margem, provocada pela açāo das correntes de maré vazante e enchente, e a ação local das correntes geradas pela incidência das ondas provenientes de S-SE e E. Esta interação gera, não apenas o recuo da Ponta do Perigo e de feiçōes arenosas, de direção geral NW-SE, como também a translação da margem do canal para NW, a partir de um ponto imaginário situado na interseç̧ão da direção geral da linha de costa, SW-NE com o alinhamento desta margem.

Finalmente, o acesso ao canal profundo da desembocadura lagunar de Cananéia é dificultado por bancos arenosos submersos dispostos quase paralelamente à linha de costa atual representando o resultado da interação entre as correntes de maré e de deriva litorânea. Estes bancos submersos, conforme Suguio \& Tessler (1983), são alimentados por areias carreadas pela corrente de maré vazante, originárias das margens das ilhas Comprida e Cardoso, bem como relacionadas aos sedimentos relíquia da plataforma continental interna.Os bancos submersos expandem-se, mantendo seu perfil de equilíbrio instável, até o nível de agradação máximo, quando então passam a ser erodidos pelos mesmos processos hidrodinâmicos costeiros (correntes de deriva litorânea, ondas e correntes de maré) que haviam gerado a sua agradação.

A arrebentação de ondas diretamente sobre os bancos arenosos, quando estes atingem a superfície das águas, novamente libera os sedimentos para o transporte pelas correntes de deriva, deslocando-os para outros depocentros. 


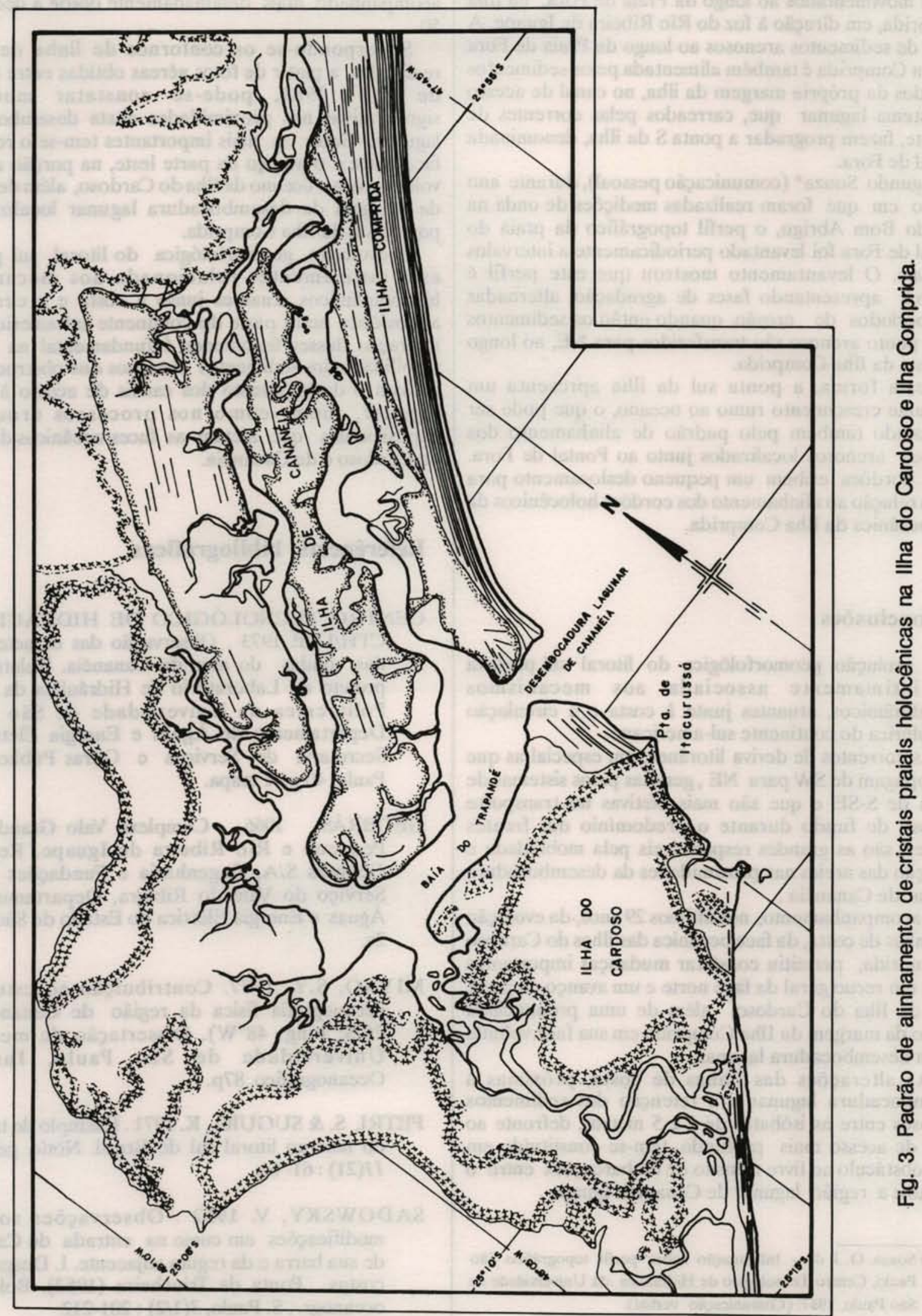


Os sedimentos retrabalhados desses bancos arenosos submersos de grande mobilidade e que impossibilitam o estabelecimento de um canal único de acesso à região lagunar, são novamente capturados pelas correntes de deriva litorânea, de sentido predominante NE, e movimentados ao longo da Praia de Fora, na Ilha Comprida, em direção à foz do Rio Ribeira de Iguape. A carga de sedimentos arenosos ao longo da Praia de Fora da Illha Comprida é também alimentada pelos sedimentos erodidos da própria margem da ilha, no canal de acesso ao sistema lagunar que, carreados pelas correntes de vazante, fazem progradar a ponta $S$ da ilha, denominada Pontal de Fora.

Segundo Souza* (comunicaçāo pessoal), durante ano e meio em que foram realizadas mediçōes de onda na Ilha do Bom Abrigo, o perfil topográfico da praia do Pontal de Fora foi levantado periodicamente a intervalos mensais. O levantamento mostrou que este perfil é instável, apresentando fases de agradaçẩo, alternadas com períodos de erosāo, quando entāo os sedimentos deste ponto arenoso sāo transferidos para NE, ao longo da costa da Ilha Comprida.

Desta forma, a ponta sul da ilha apresenta um constante crescimento rumo ao oceano, o que pode ser constatado também pelo padrāo de alinhamento dos cordōes arenosos localizados junto ao Pontal de Fora. Estes cordōes exibem um pequeno deslocamento para W em relação ao alinhamento dos cordões holocênicos da face oceânica da Ilha Comprida.

\section{Conclusões}

A evolução geomorfológica do litoral sul paulista está intimamente associada aos mecanismos hidrodinâmicos, atuantes junto à costa e à circulação atmosférica do continente sul-americano.

As correntes de deriva litorânea, em especial as que se propagam de SW para NE, geradas pelos sistemas de ondas de S-SE e que são mais efetivas no transporte arenoso de fundo durante o predomínio das frentes polares, são as grandes responsáveis pela mobilidade e retenção das areias nas proximidades da desembocadura lagunar de Cananéia .

O acompanhamento, nos últimos 29 anos, da evolução das linhas de costa, da face oceânica das ilhas do Cardoso e Comprida, permitiu constatar mudanças importantes como um recuo geral da face norte e um avanço da parte leste da Ilha do Cardoso, além de uma pronunciada erosāo da margem da Ilha Comprida em sua face voltada para a desembocadura lagunar.

As alteraçōes das linhas de costa, próximas à desembocadura lagunar e a retenção dos sedimentos arenosos entre as isóbatas de 1 e 5 metros, defronte ao canal de acesso mais profundo, têm-se constituído em sério obstáculo ao livre trânsito de embarcaçōes entre o oceano e a região lagunar de Cananéia-Iguape .

(*) Souza, O. J. de - Informaçấo sobre perfil topográfico. São Paulo, Centro Tecnológico de Hidráulica da Universidade de São Paulo, 1987. (Comunicação verbal).

\section{Resumo}

O processo evolutivo da desembocadura lagunar de Cananéia, principal canal de interligação entre o oceano e a região lagunar de Cananéia-Iguape (SP), vem sendo acompanhado mais detalhadamente desde a década de 50 .

Superpondo-se os contornos de linha de costa, realizados a partir de fotos aéreas obtidas entre os anos de 1952 e 1981, pode-se constatar mudanças significativas nas proximidades desta desembocadura lagunar. Entre as mais importantes tem-se o recuo da face norte e o avanço da parte leste, na porçāo arenosa voltada para o oceano da Ilha do Cardoso, além de erosão da margem da desembocadura lagunar localizada na porção sul da Ilha Comprida.

A evoluçāo geomorfológica do litoral sul paulista está intimamente relacionada aos mecanismos hidrodinâmicos atuantes junto à costa e a circulação atmosférica nesta parte do continente sul-americano. A interaçāo desses fenômenos é fundamental na intensa mobilidade dos sedimentos arenosos que obstruem e/ou causam o deslocamento dos canais de acesso à região lagunar, bem como nos processos erosivos e deposicionais que afetam as faces oceânicas das ilhas do Cardoso e de Cananéia.

\section{Referências bibliográficas}

CENTRO TECNOLÓGICO DE HIDRÁULICA CTH/USP. 1973 . Observaçāo das características das ondas do mar de Cananéia. Relatório de projeto do Laboratório de Hidráulica da Escola Politécnica da Universidade de São Paulo, Departamento de Águas e Energia Elétrica da Secretaria de Serviços e Obras Públicas, São Paulo, 40 p., 1 mapa.

GEOBRÁS. 1966. Complexo Valo Grande, Mar Pequeno e Rio Ribeira de Iguape. Relatório Geobrás S/A, Engenharia e Fundaçōes para o Serviço do Vale do Ribeira, Departamento de Águas e Energia Elétrica do Estado de Sāo Paulo. $2 v$.

MIYAO, S.Y. 1977. Contribuição ao estudo da oceanografia física da regiảo de Cananéia (lat. $25^{\circ} \mathrm{S}$; long. $48^{\circ} \mathrm{W}$ ). Dissertação de mestrado. Universidade de São Paulo, Instituto Oceanográfico. 87 p.

PETRI, S. \& SUGUIO, K. 1971 . Exemplo de trabalho do mar no litoral sul do Brasil. Notíc. geomorf., 11(21) : 61- 66 .

SADOWSKY, V. 1952 . Observaçōes sobre as modificações em curso na entrada de Cananéia, de sua barra e da região adjacente. I. Desgaste das costas . Ponta da Trincheira (1952). Bolm Inst. oceanogr. , S. Paulo, 3(1/2) : 201-212. 
SADOWSKY, V. 1954 . Novas contribuiçōes ao estudo da entrada da barra de Cananéia. Bolm Inst. oceanogr., S. Paulo, 4(1/2) :151-177.

SUGUIO, K. \& TESSLER, M. G. 1983. Intense coastal sedimentation and erosion in the Cananéia outlet, southern State of São Paulo, Brazil. Bolm Inst. oceanogr., S. Paulo, 32(1):71-75.
TESSLER, M.G. 1988. Dinâmica sedimentar quaternária ' no litoral sul paulista. Tese de doutorado. Universidade de São Paulo, Instituto de Geociências. 276 p. )

(Recebido em 07-11-89; aceito em 2408-90) 